https://doi.org/10.12913/22998624/123007

\title{
Temperature Measurement of Modern Cutting Tools During Turning
}

\author{
Karol Grochalski ${ }^{*}$, Piotr Jabłoński', Rafał Talar', Paweł Twardowski', \\ Michał Wieczorowski', Bartosz Jakubek' ${ }^{1}$, Wojciech Rukat ${ }^{1}$ \\ 1 Faculty of Mechanical Engineering, Poznan University of Technology, Piotrowo 3, 60-965 Poznań, Poland \\ *Corresponding author's e-mail: karol.grochalski@put.poznan.pl
}

\begin{abstract}
The study presents the influence of the anti-wear coatings and the type of material from which the cutting tools are made of on the cutting temperature occurring on the tool. The cutting tools made of boron nitride and tungsten carbide composite were investigated. The methodology of measuring the cutting temperature using the thermoelement and thermovision techniques was presented. The results of the temperature measurements occurring on the cutting tool in the cutting zone were compared. The paper also presents a method of determining the effective emissivity of the tested tools, necessary for the correct temperature measurement using the non-contact method. The obtained data were interpreted and the relationships described, and then the results obtained were discussed.
\end{abstract}

Keywords: cutting tools, tool wear, cutting temperature, temperature measurement, thermographic techniques, emissivity coefficient

\section{INTRODUCTION}

Cutting tools, through their manufacturing process, obtain specified geometry and physical properties which allows their application in the machining operations. During machining, the cutting tools are exposed to aggressive conditions, which results in a significant change of their initial properties. The most significant damages refer to a change in geometry of cutting edge, destruction of the coating and surface of tool as well as degradation of both the physical and chemical properties of the cutting tool material. Deterioration of the physical properties of a cutting tool results in a decrease of the machining capability of a tool [1] which is caused by different wear processes occurring under the cutting conditions. The occurrence of specific types of wear processes depends on numerous factors, e.g. the combination of the tool and machined material, as well as the parameters of cutting speed, feed, and depth. Intensity and the type of wear phenomenon directly affect the lifespan of a tool, consequently also influencing the economic efficiency of the machining processes $[2,3]$.
Numerous destructive processes connected with tool wear can be enumerated, such as abrasive wear, cutting tool fracture, adhesive wear, diffusion phenomena and chemical wear. Other mechanisms, like electrochemical wear, fatigue damage or plastic deformation of tool also take significant part in total tool wear. The described mechanisms of wear can occur simultaneously or separate; with varying intensity, and under different machining conditions [4].

The research on the influence of the temperature increase on the intensity of life time of cutting tools made of various materials, including boron nitride, can be found among the available literature $[5,6,7]$. The results presented in these publications clearly show that significant variations of the cutting temperature, depending not only on the machining parameters but also on the machined material, can be analyzed.

In paper [8], the authors included a report of the research on the influence of the machining parameters, machined material hardness and temperature on tool flank wear. The increase of the wear intensity along with the cutting temperature are caused by the changes in 
the mechanical properties of tool material e.g. decrease of hardness and intensification of other mechanisms of wear-chemical one and adhesive phenomena. In the case of super-hard materials, like PCD (polycrystalline diamond) or cBN (cubic boron nitride), despite their superior resistance to abrasive wear, an increase in the cutting temperature significantly decreases the tool life. This can be connected with the intensity of the adhesive wear phenomena, which in high temperatures take a significant part in the total tool wear [9]. Therefore, it can be assumed that the significant tool life improvement of super hard cutting tools can be obtained by the limitation of the cutting temperature. These issues have been described in greater detail in publications $[10,11]$. Implementation of continuous on-line temperature measurement as well as determination of the temperature values and trends enables to specify the types of wear that occur during machining. The adhesive processes can become the reason for both increased wear rate of tool and high roughness of machined surface [12].

The adhesion phenomenon, which consists of simultaneous creation and destruction of the clings between the surfaces staying in contact, is a process that generates excessive amounts of heat. Because of that, the temperature measurement can be a useful tool in detecting the occurrence of this process. Noticeable deviations in the trends of temperature increase with increasing cutting speed can be caused by the mechanism of wear different that abrasive [13].

\section{MATERIAL}

In order to increase the machining efficiency and tool life, materials different than popular carbides may be adopted. In the high-speed machining techniques of metallic materials, the application of super-hard materials like polycrystalline diamond and cubic boron nitride can be considered [14]. Modern trends, highlighted in the machining strategies in processing some of both ferrous and non-ferrous metals within automotive industry assume the application of high speed machining (HSM), which can increase the tool wear rate in some cases. Therefore, the application of the materials of superior wear resistance, especially under the conditions of increased temperature, is justified. Cubic boron nitride (cBN), due to its mechanical properties, is a suitable material for the cutting tools. Compared to the known and widely adopted tool materials, cBN presents higher hardness, resistance to wear and corrosion, as well as good chemical and thermal durability. Still, boron nitride shows some important drawbacks, significantly limiting its application field [15]. These disadvantages are mainly connected with poor resilience and tool shaping problems. In order to overcome these drawbacks, some composite materials were implemented, consisting of boron nitride and other materials.

The composite of cBN and WCCo (tungsten carbide-cobalt) is a new composite manufactured with the pulse plasma sintering method, with the volume of boron nitride amounting to $30 \%$. The manufactured materials are characterized by comparable hardness and increased resilience, in comparison to pure $\mathrm{cBN}$, which allows expanding the field of application of this material for the cutting tools. There are publications, proving good performance of the tools manufactured of the WCCo-cBN composite [16,17]. Therefore, the authors decided to perform this research with the tests focused on the temperature measurement.

\section{METHOD}

The temperature measurements were conducted on CNC (computer numerical controlled) lathe CTX 210 by DMG. During the tests described in this paper, a turning tool with geometry similar to the grooving tool (type "7" according to ISO 243) was employed. The comparison tests of cutting temperature for two different materials - aluminum casting alloy AlSil3Mg1CuNi and cast iron EN GJL 250 were conducted. For these two materials, the tests with three different tools were performed. The tested tool was made of the described WCCo-cBN composite. This cutting insert was fabricated in three variations; without coating and with two anti-wear PVD coatings, i.e. TiAlN and TiN; finally resulting in six combinations of tools and machined materials. For each kind of insert and machined material, the tests of the tool temperature during grooving with constant cutting speed were performed. The machined grooves were $3 \mathrm{~mm}$ deep and $2.8 \mathrm{~mm}$ wide. The width of the groove was the result of the tool geometry. The tests were performed for various combinations of cutting speeds and feeds. In the case of machining both materials, the cutting speeds were set to $125,150,175,200,225$ 
and $250 \mathrm{~m} / \mathrm{min}$. Moreover, in the case of aluminum alloy high cutting speeds of 700, 1000 and $1500 \mathrm{~m} / \mathrm{min}$ were adopted. For each cutting speed, tests were performed with feed rate of 0.06 and $0.1 \mathrm{~mm} / \mathrm{rev}$. The workpiece diameter changed during machining from 130 to $100 \mathrm{~mm}$. In order to decrease vibrations and ensure better fixing of the machined shaft, a three clamp pneumatic chuck along with a tool holder were adopted for these operations. Between the temperature measurement sequences, appropriate break time was taken, so the cutting edge could cool down to ambient temperature, which varied from $21^{\circ} \mathrm{C}$ to $23^{\circ} \mathrm{C}$. All machining operations were performed without coolant. The cutting temperature measurements were performed with two methods: thermographic and contact.

\section{DETERMINATION OF EMISSIVITY PROPERTIES OF TESTED MATERIALS}

The basic trait of the thermographic measurements is a non-direct way of temperature measurement; these methods enable to directly measure the power of infrared radiation emitted by object. Radiation is converted by a thermographic sensor into an electric signal, which expresses the temperature of the measured object. The temperature values are determined based on the information about the thermometric characteristics of a thermal imaging camera and the environment conditions. Besides the radiation emitted by the object, also background radiation reflected by the object and atmosphere radiation arrived to the sensor element. The knowledge about the value of effective emissivity coefficient is crucial to ensure the correctness of thermographic measurement $[18,19]$. Emissivity is a parameter describing the radiation properties of the measured object, and is hard to estimate. The emissivity properties are determined by numerous factors, like the type of material, the roughness of surface, radiation angle, wavelength and temperature [20]. in the case of the metallic materials, emissivity increases along with temperature, but in the case of the non-metallic materials, this relation is opposite. Emissivity, as a function of temperature, is nonlinear and monotonic [21]. In order to precisely determine the emissivity parameter $\varepsilon$, which is necessary for correct estimation of temperature with thermal imaging camera, several measurements of the surface roughness of the tested cutting tool were performed. The measurement covered determination of the surface roughness parameters, and was performed with interference Veeco Wyko NT1100 coherence scanning interferometer. Emissivity coefficient $\varepsilon$, which is the most important parameter in reference to radiation temperature measurement, is strongly connected with the surface properties of the tested object, especially with its surface roughness. The studies on the impact of the surface parameters on emissivity were carried out by Majchrowski, Różański, Grochalski [22] as well as Da Wen and Mudawar [23]. Emissivity $(\varepsilon)$ decreases rapidly along with the increasing reflectivity of surface. These issues have been described in more detail in publications [24-26]. The surface topography data obtained from the measurements were presented in table [Tab 1]. The figure (Fig. 1) shows the topography of the tool surface to provide a complete set of information needed to determine the emissivity factor for the specific tool examples.

Effective magnitude of the emissivity coefficient regarding the real temperature of the cutting tools made of $\mathrm{WCCo} / \mathrm{cBN}$ with and without coatings (TiAN or TiN) was designated with FLIR T620 thermal imaging camera. The spatial (geometric) resolution of the T620 camera in the sense of IFOV (Instantaneous Field Of View) is $0.62 \mathrm{mrad}$ and the thermal resolution in the sense of NETD (Noise Equivalent Temperature Difference) is less than $0.05^{\circ} \mathrm{C}$. The limiting errors of the camera are comparable and equal to $\pm 2^{\circ} \mathrm{C}$ or $\pm 2 \%$ of the temperature readings (the greater of these two values is taken as the limiting error). This device is capable of capturing the pictures of 640x480 pixels resolution, spectral range varying from $7.5 \mu \mathrm{m}$ to $14 \mu \mathrm{m}$ and is equipped with FLIR ResearchIR MAX software. In this environment, the analysis of the thermal images obtained was carried out using the implemented tools enabling the definition of the local and global parameters for the selected measurement areas. Moreover, a laboratory heater was adopted for the emissivity coefficient determination [27]. The laboratory

Table 1. Surface roughness parameters of different cutting tools

\begin{tabular}{|c|c|c|c|}
\hline \multicolumn{4}{|c|}{ Parameters of surface roughness of cutting tools } \\
\hline \multicolumn{2}{|c|}{ Parameter } & $\mathrm{Sq}$ & Sz \\
\hline \multirow{3}{*}{$\begin{array}{l}\text { Tool } \\
\text { material / } \\
\text { coating }\end{array}$} & WCCo/cBN & $0.23 \mu \mathrm{m}$ & $2.05 \mu \mathrm{m}$ \\
\hline & WCCo/cBN + TiAIN & $0.29 \mu \mathrm{m}$ & $2.90 \mu \mathrm{m}$ \\
\hline & WCCo/cBN + TiN & $0.27 \mu \mathrm{m}$ & $2.28 \mu \mathrm{m}$ \\
\hline
\end{tabular}




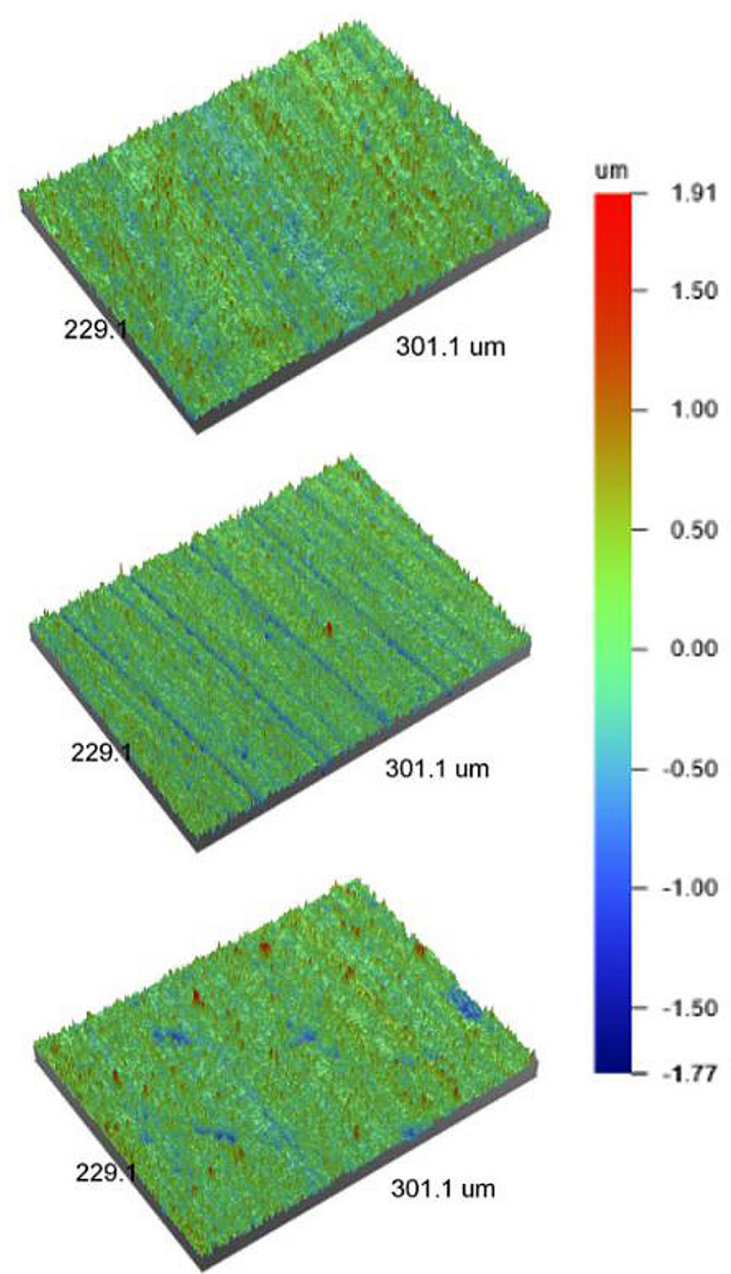

Fig. 1. Surface topography of cutting tools: a) WCCo/ $\mathrm{cBN}, \mathrm{b}) \mathrm{WCCo} / \mathrm{cBN}+\mathrm{TiAlN} \mathrm{c)} \mathrm{WCCo} / \mathrm{cBN}+\mathrm{TiN}$

heater was equipped with a holder for cutting tool fixture, ensuring constant and homogenous temperature on all measured surface. A complete station for emissivity designation was presented in figure 2 . The temperature of the specimen placed in the heater was measured using the same measuring system, which was used to measure the cutting tools temperature in the cutting process.

The measurement data of effective emissivity of the tested tools were presented as a chart in figure 3 . The emissivity coefficient $\varepsilon$ was adapted for real radiation temperature measurement during cutting. The values of the emissivity parameter for different temperatures were assumed from curve of characteristics (Fig. 3), for the temperature ranges achieved with the contact method.

The achieved characteristics are typical for the non-metallic materials. The tools coated with TiAlN have the highest magnitude of emissivity among all tested samples, because of different surface structure, lower reflectivity and its chemical composition. During the thermographic measurement, the higher value of emissivity coefficient ensures higher precision and lower relative error.

\section{TESTS RESULTS}

The temperature measurements with a thermal imaging camera were performed for the tools made of WCCo/cBN coated with TiAlN and without coating because of satisfying emissivity coefficient value or these tools [28]. In case of tools coated with TiN, measurements with thermographic techniques are very difficult and in that case were abandoned, as effective coefficient of emissivity was lower than $\varepsilon=0.16$. The thermographic measurements were performed with same measurement point (for each tool) that is in the case of the contact method with thermoelement, with same machining parameters and conditions. A thermal imaging camera was placed inside the NC lathe DMG CTX 210, within a distance from object that ensured best geometrical resolution. Placement of the thermal imaging camera in reference to the machined object and the tested tool was presented in Figure 4. The results of the conducted tests were presented on graphs.

The graphs present the maximum temperature of the cutting edge during the machining of cast iron (grey cast iron EN GJL 250, Fig. 5a and $5 \mathrm{~b}$ ) and aluminum alloy (A1Si13Mg1CuNi, Fig. 5c and 5d) with cutting speeds varying from $125 \mathrm{~m} / \mathrm{min}$ to $250 \mathrm{~m} / \mathrm{min}$ and feed rates of $0.06 \mathrm{~mm} / \mathrm{rev}$ and $0.1 \mathrm{~mm} / \mathrm{rev}$. The presented results were realized with a thermal imaging camera, and can be either verified or compared with the results achieved with the contact method that adopted a thermoelement. It can be concluded that the cutting temperature increases with the cutting speed and federate. This correlation can be easily seen on the graphs of the measured temperature for the cast iron machining. In the case of aluminum alloy machining, the cutting temperature increases until reaching specific value, and then it starts to decrease along with the increasing cutting speed. A decrease in the cutting temperature can be easily noticed during machining with high cutting speeds, over $700 \mathrm{~m} / \mathrm{min}$. These results were presented on charts (Fig. 6). An increase in the feed rate effects in the temperature growth; this correlation seems to be unaffected by the changes in the cutting speed. 


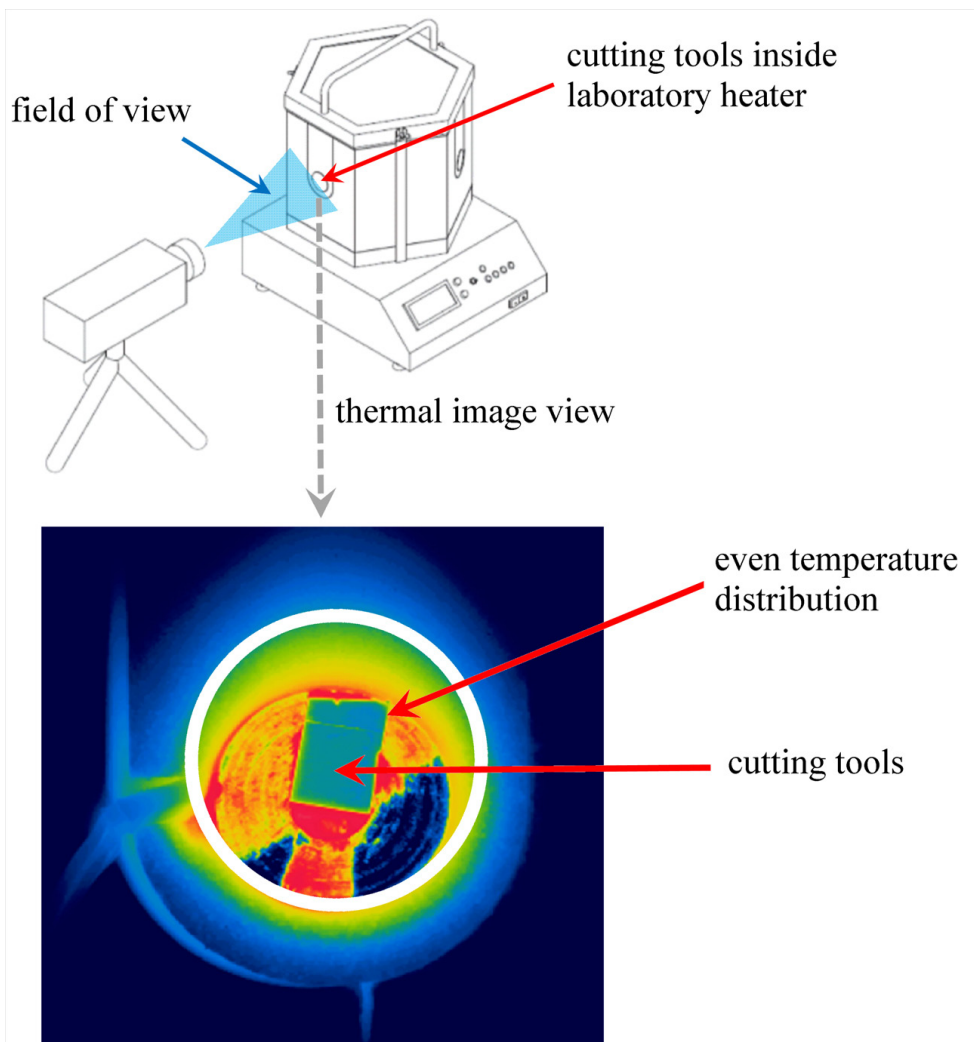

Fig. 2. Station for emissivity parameter determination

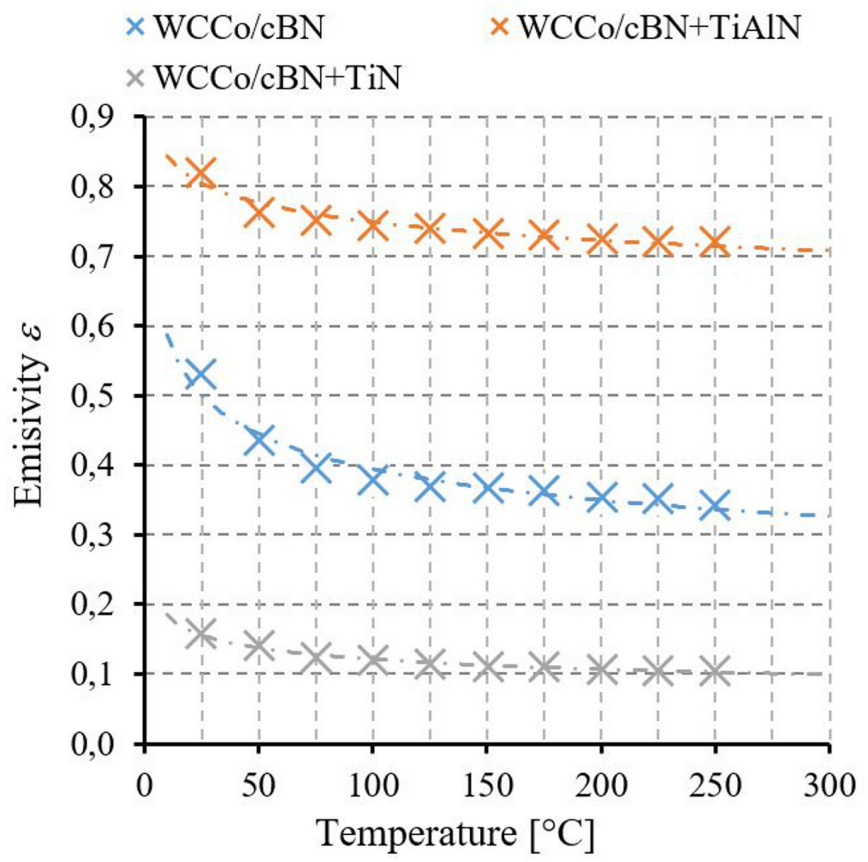

Fig. 3. Graph of emissivity coefficient values, depending on temperature for tested cutting tools with different coatings

The temperature measured with the thermographic method, similarly to the results achieved with the contact method, shows a monotonic increase along with the cutting speed. On the basis of this data it can be concluded that the TiAlN coating application effects in lower cutting temperature during turning. It is caused by a lower friction coefficient of this material, as well as a decrease of the adhesion intensity. 


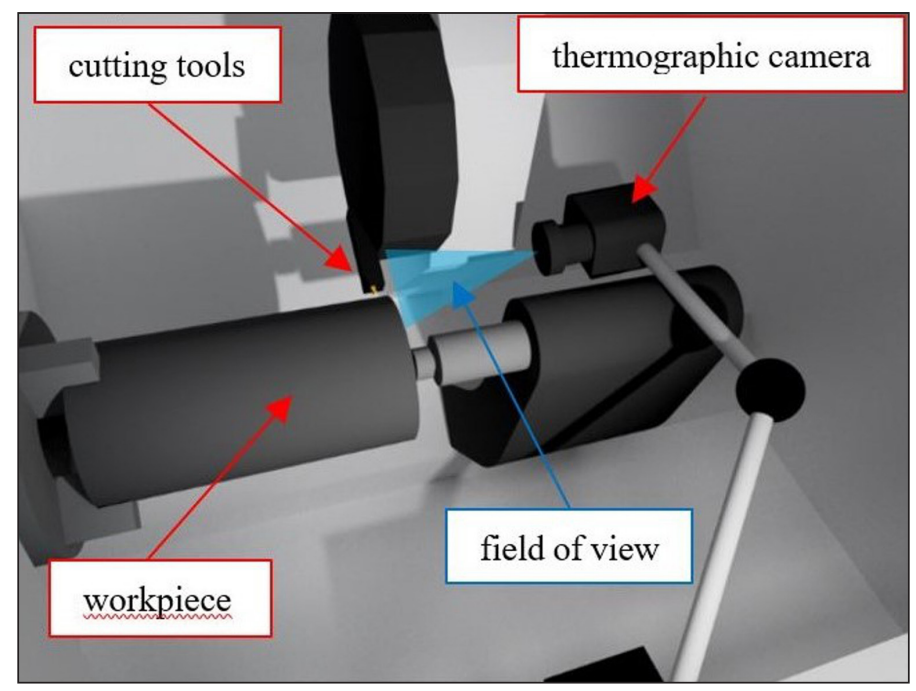

Fig. 4. Testing station inside NC lathe and placement of the thermal imaging camera in reference to the measured object

a)

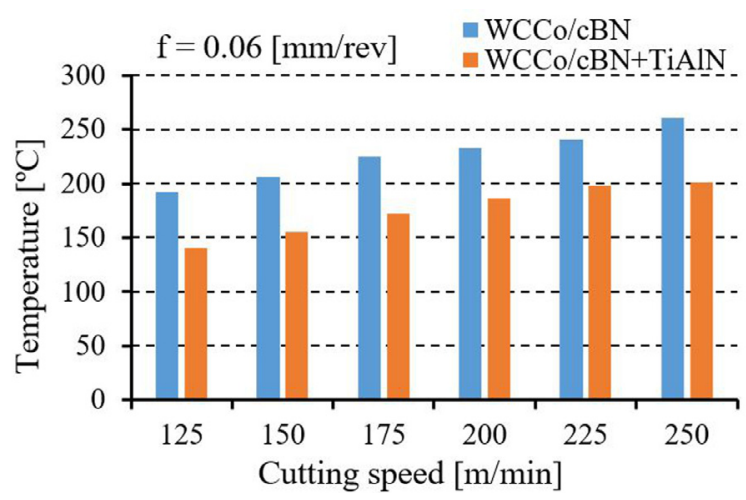

c)

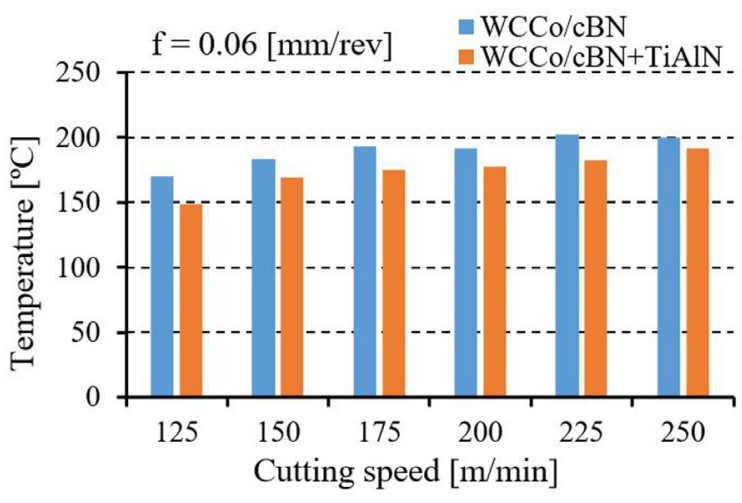

b)

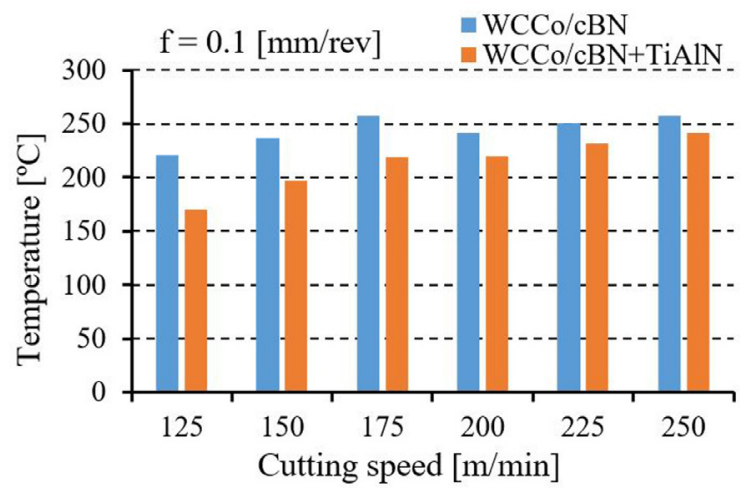

d)

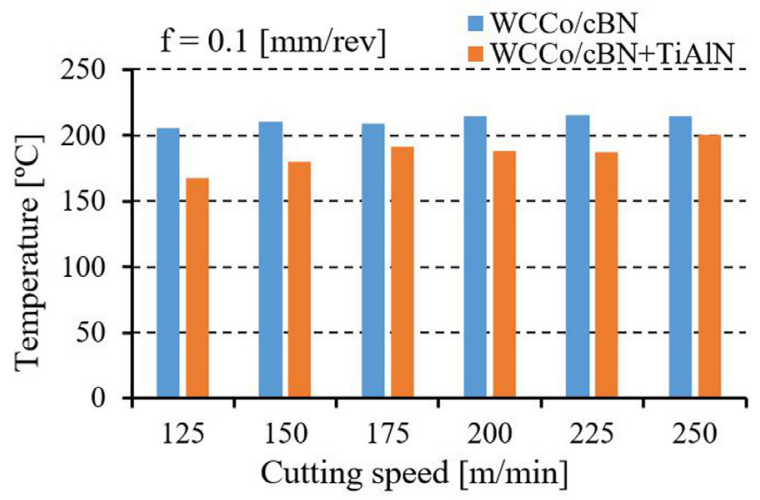

Fig. 5. Temperature $(\max )$ depending on the cutting speed and feed rate for cast iron $(\mathrm{a}, \mathrm{b})$ and aluminum alloy (c,d) machining - thermographic method

\section{CONTACT MEASUREMENT}

The temperature measurement during machining was performed with the contact method, using $0.9 \mathrm{~mm} \mathrm{~K}$ - type thermoelement (NiCr$\mathrm{NiAl)}$ and National Instruments measurement hardware along with the LabVIEW software. The limiting errors of the measure system are comparable and equal to $\pm 0.5^{\circ} \mathrm{C}$. Contact measurement required the manufacturing of a blind hole inside plane of tool, in order to place thermoelement as close as possible to the cutting area. This operation was performed with electro discharge machining (EDM). The blind hole in the tool was 
a)

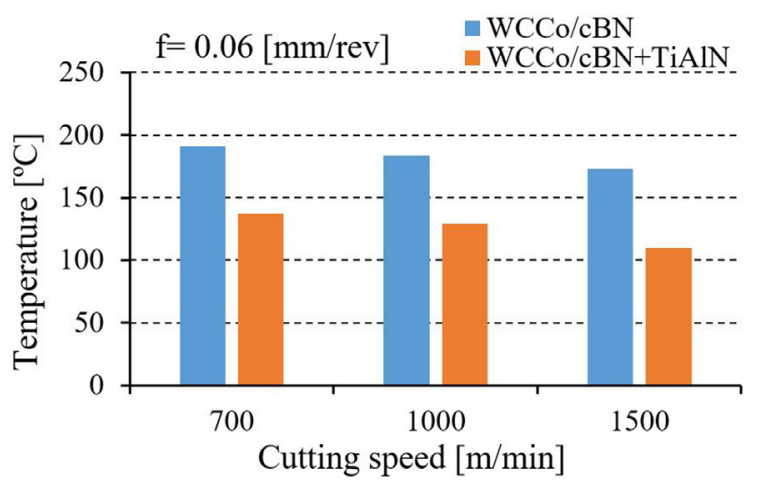

b)

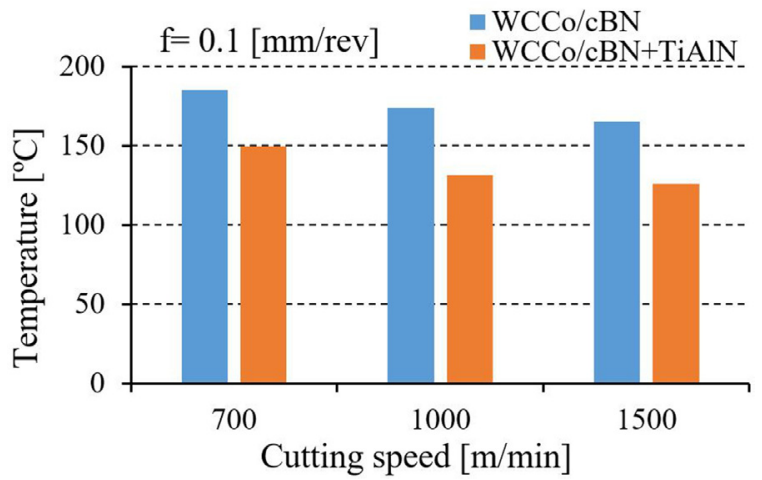

Fig. 6. Temperature (max) depending on the cutting speed and feed rate for aluminum alloy machining - thermographic method

manufactured in the direction perpendicular to the feed vector during test. Images (Fig. 7) present the placement of the thermoelement inside cutting edge. The sensor was placed inside the cutting edge, staying in contact with the tool material via thermoconducting paste.

The results of these tests were shownon charts. These charts (Fig. 8) present variations of temperature for different feed rates. For the feed rate $\mathrm{f}=0.06 \mathrm{~mm} / \mathrm{rev}$ (Fig. $8 \mathrm{a}$ ) the temperature during the cast iron machining, at the end of groove cutting sequence presents the signs of temperature stabilization. In the case of the feed rate $\mathrm{f}=0.1 \mathrm{~mm} / \mathrm{rev}$ (Fig. $8 \mathrm{~b}$ ), the measured temperature is higher in its peak than the temperature for a lower feed rate; moreover, close to the end of the cutting sequence, the temperature is not stabilized. Therefore, it can be assumed that with the cutting temperature would increase along with the feed rate. Charts (Fig. 9) present the aggregated results of the influence of the applied tool coating on the cutting temperature, in regard to the machining parameters cutting speed and feed rate $[29,30]$. These charts present the results of tests for both cast iron (Fig. 9a and 9b) and aluminum alloy (Fig. 9c and 9d) machining.
The charts presented in Figure 11 show the aggregated results of the cutting temperature for different cutting speeds, feed rates, and tool coating. In that case, the adopted cutting speeds were significantly higher than during the previous test. One should note a decrease in temperature along with the increasing cutting speed.

\section{TEMPERATURE DISTRIBUTION}

The thermographic measurements of temperature, besides the information about temperature magnitude at the specific point, can also provide complex data concerning the temperature distribution along the tested surface. During the conducted experiment, it was noted that heat is also transmitted to the cutting tool via chips occurring during machining. Chips transfer the energy on tool both by friction and in thermal ways. This process was captured on the thermographic images (Fig. 12.).

In Figure 13, one can observe the surface condition of aluminum alloy machined witch a $\mathrm{WCCo} / \mathrm{cBN}$ tool without the anti-wear coatings. The grooves were machined one by one
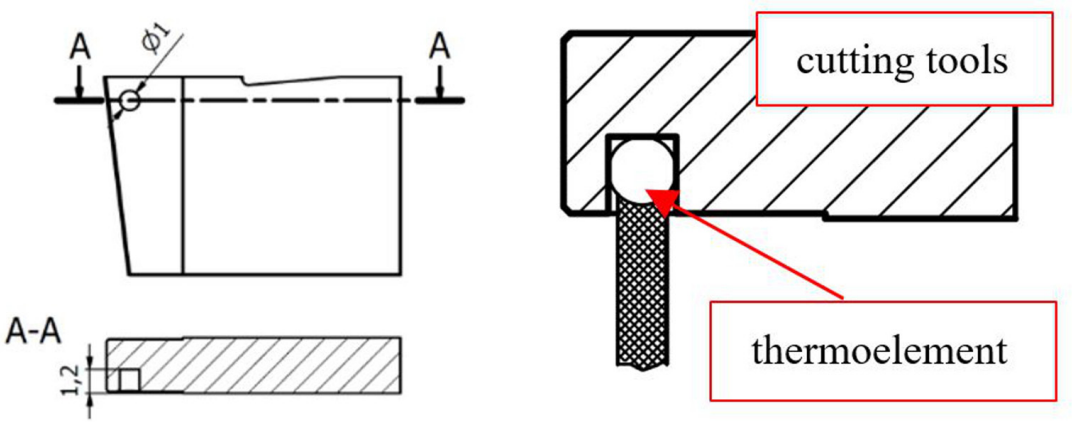

Fig. 7. Blind hole for thermoelement placement and thermoelement inside cutting edge 
a)

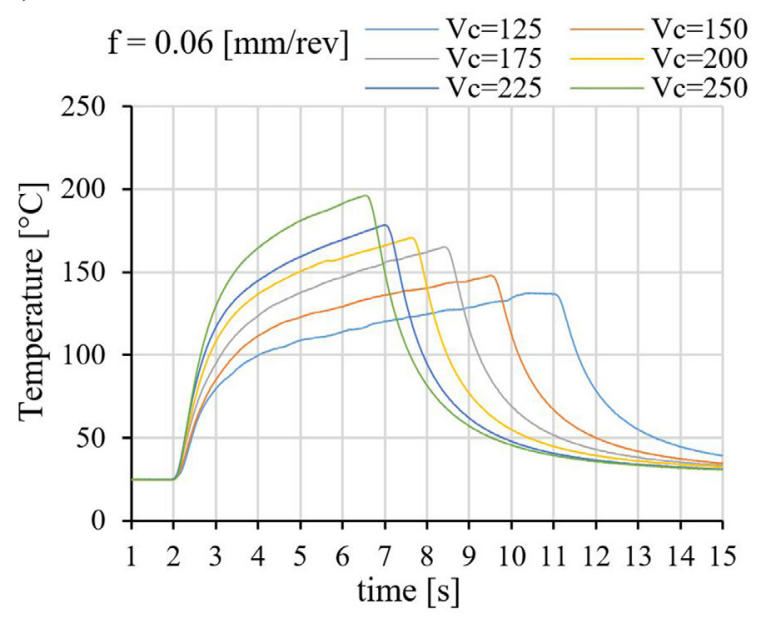

b)

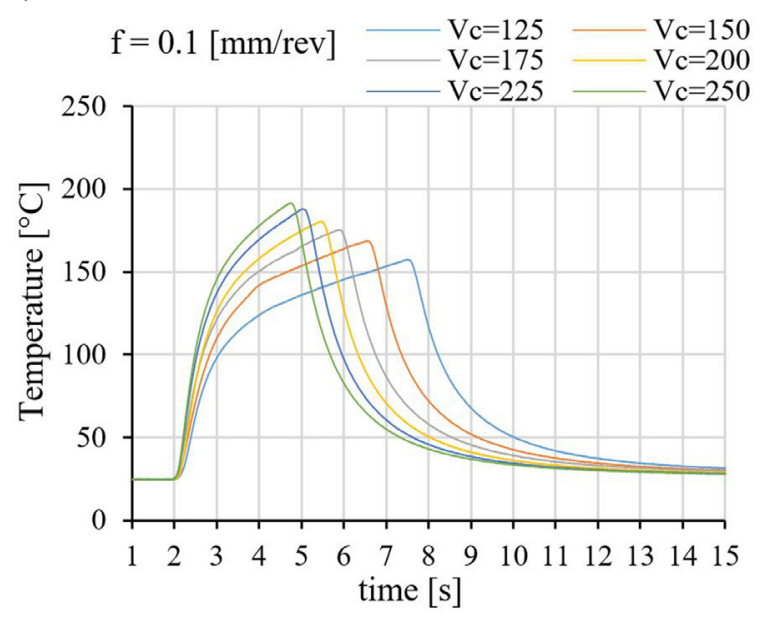

Fig. 8. Changes of temperature during grooving of the EN GJL 250 cast iron with the WCCo-cBN tool at different cutting speeds and feed rates

a)

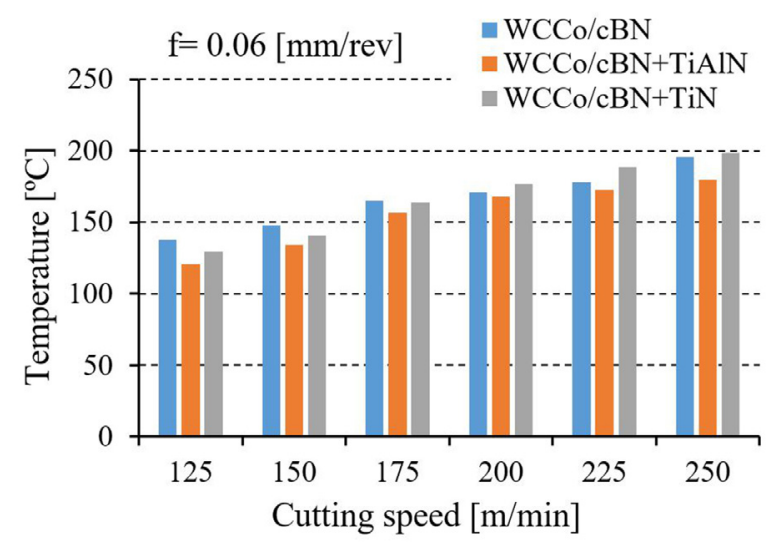

c)

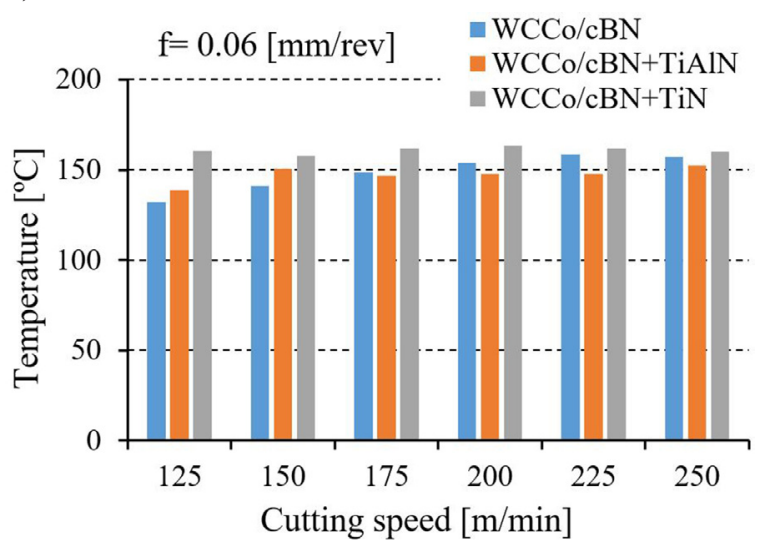

b)

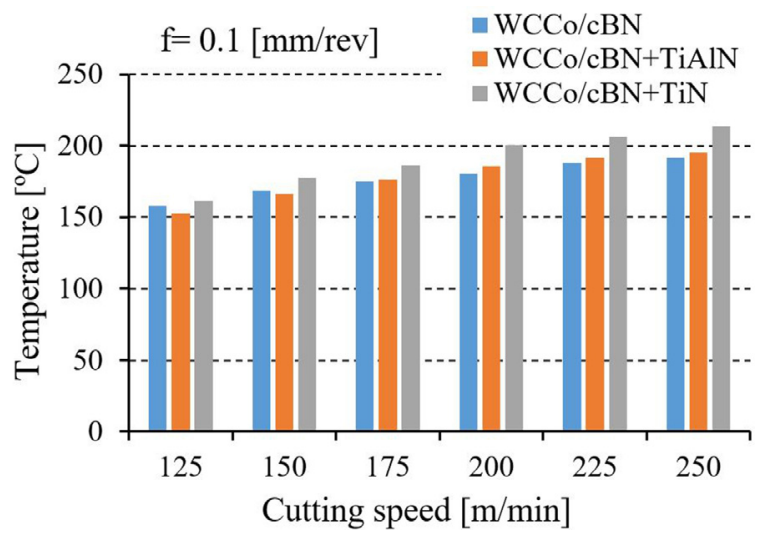

d)

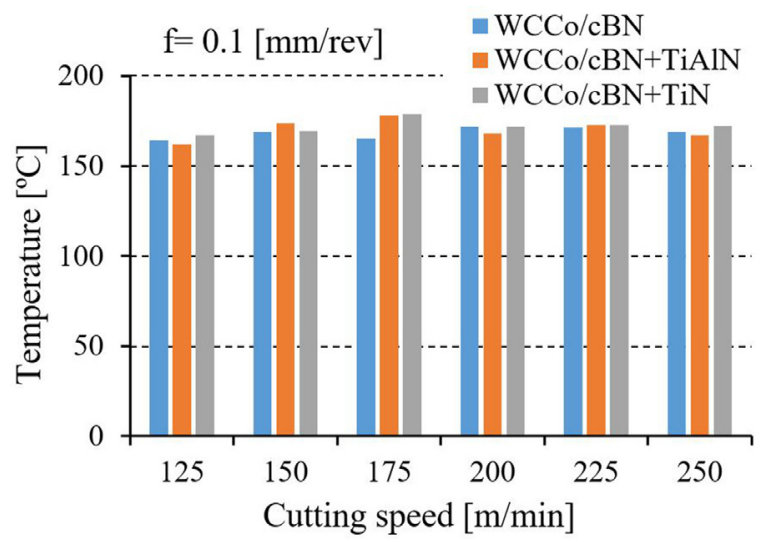

Fig. 9. Temperature depending on the cutting speed and feed rate for cast iron (a,b) and aluminium alloy (c,d) machining - contact method

from the side of tailstock to the side of main spindle of lathe, with an increasing cutting speed. The area machined with high cutting speeds (700-1500 $\mathrm{m} / \mathrm{min}$ ) was described with number 1 , while the area machined with low cutting speeds $(125-250 \mathrm{~m} / \mathrm{min})$ was described with number 2 .
On area 2, one can easily observe significantly higher surface roughness than on area 1. Even without the microscopic equipment, one can see the marks of material extraction from the surface of area 2. The reflective surface of area 1 does not show signs of these. On the basis of these analyses, 
a)

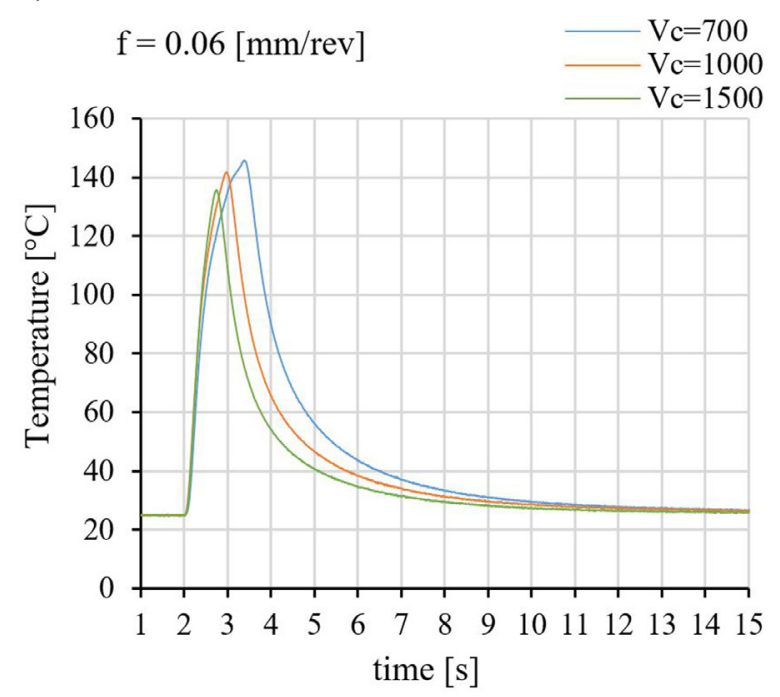

b)

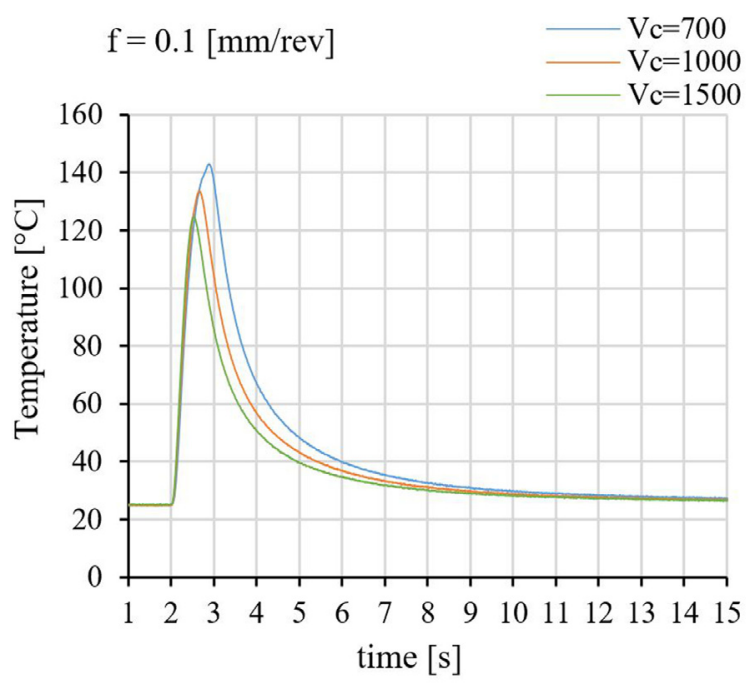

Fig. 10. Changes of temperature during grooving of the EN GJL 250 aluminum alloy with the WCCo-cBN tool at different cutting speeds and feed rates

a)

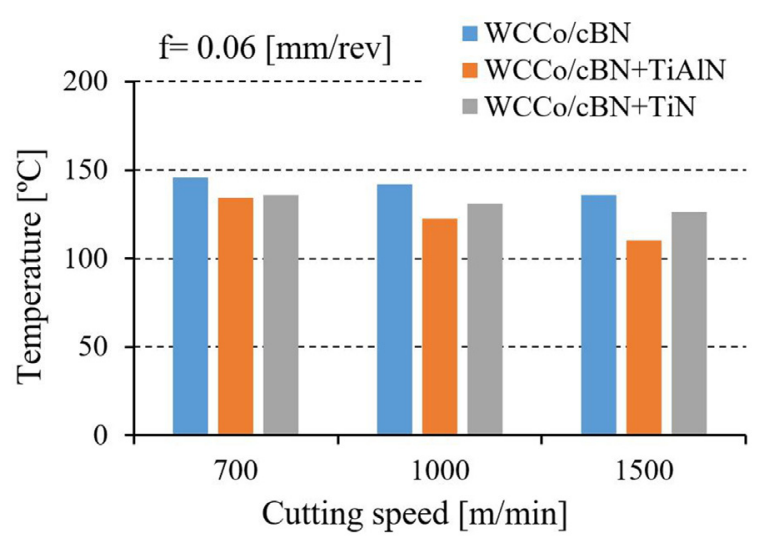

b)

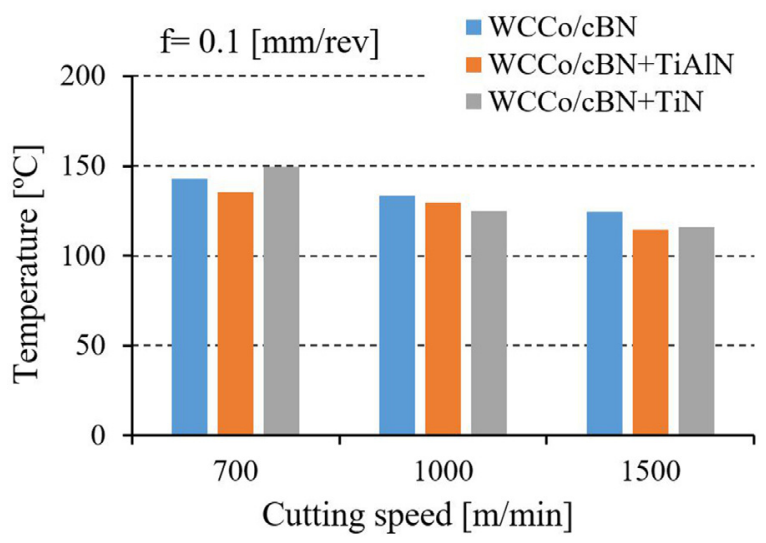

Fig. 11. Temperature depending on the cutting speed and feed rate for aluminum alloy machining with high cutting speeds - contact method

it can be stated that intense adhesion phenomenon occurs in the area of low cutting speed (number $2)$; through the simulations creating and destroying of material bonds between tool and machined material, the deterioration of surface quality was noticed. Along with the increasing cutting speed, the signs of adhesive wear disappear, resulting in better surface quality. After the analysis, it can be concluded that an increase in the cutting speed can effect in an increased tool lifespan, as the adhesion wear is significantly eliminated, at least in that specific case.

\section{CONCLUSIONS}

The thermographic methods during the cutting temperature measurement are exposed to a significant interference of chips, which can cause errors by obstructing the measurement area. Precise designation of the emissivity coefficient in the expected temperature range is essential in preparing the thermographic measurements. The main advantage of the thermographic method of temperature measurement is the possibility of estimating temperature in any visible point of the tested object. The non-contact temperature measurement significantly eliminates the issue of thermal inertia of thermoelement adopted in the contact method. The measurement with a thermoelement shows better resistance to the obstructions of the measurement process. The sensor element a thermoelement is placed inside the tested object, which protects it from the external factors, disturbing the measurement. The main disadvantage of this method is the possibility of 


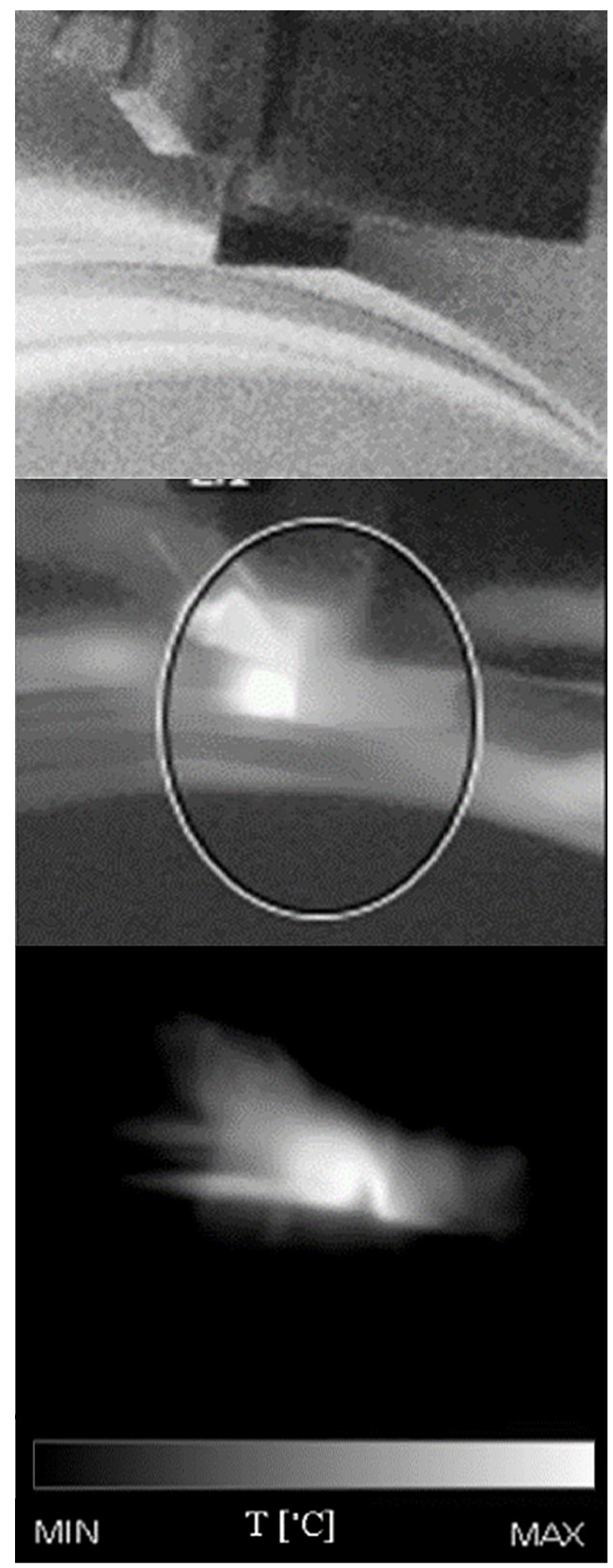

Fig. 12. Distribution and field of temperature between chips and cutting edge

measuring only one preselected point and a need for ensuring a continuous contact between the measured object and the sensor element. Moreover, in this very case, the machining hole of small diameter in the tool material was problematic. Additionally, the fabricated hole deteriorates the load bearing capabilities of the cutting

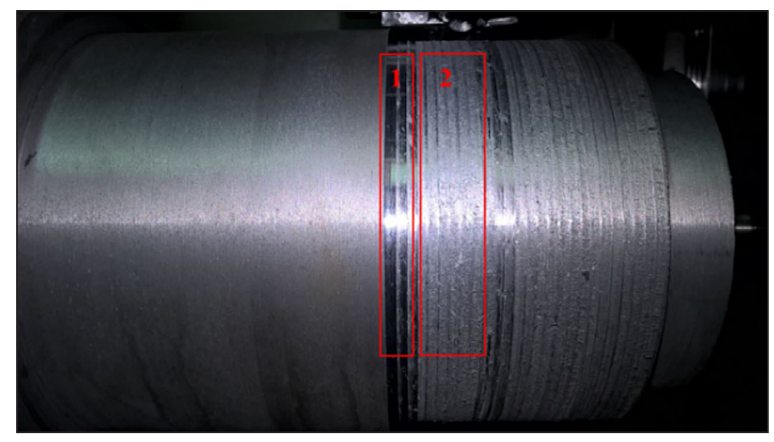

Fig. 13. Surface of the machined specimen - aluminum alloy: 1) $\mathrm{Vc}=700 \div 1500 \mathrm{~m} / \mathrm{min}$,

2) $\mathrm{Vc}=125 \div 250 \mathrm{~m} / \mathrm{min}$

tool, which can cause tool destruction by the cutting forces. In the case of low cutting speeds (under $250 \mathrm{~m} / \mathrm{min}$ ), monotonic temperature increase along with cutting speeds was recorded. In the case of the cast aluminum alloy, the application of high cutting speeds, over $700 \mathrm{~m} /$ min effected in a significant temperature drop. The cutting temperature decrease, along with a noticeable machined surface quality increase can suggest lesser intensity of the adhesion phenomena. An increase of radial federate raised the maximum recorded temperature, without obstructing the recorded trends.

The presented results show that the application of anti-wear coatings, especially TiAlN in the majority of cases (variations of machining parameters and machined material) decreases the machining temperature. This correlation can be connected with a decrease in the adhesion wear rate and lower frictional coefficient between the cutting tool material and machined material.

\section{REFERENCES}

1. Monka P., Monkova K., Balara M., Hloch S., Rehor J., Andrej A., Somsak M. (2016). Design and experimental study of turning tools with linear cutting edges and comparison to commercial tool, The International Journal and Advanced Manufacturing Technology, 85, 2325-2343. DOI: 10.1007/ s00170-015-8065-3.

2. Aslantas K., Ucun I., Cicek A. (2012). Tool life and wear mechanism of coated and uncoated Al2O3/ TiN mixed ceramic tools in turning hardened alloy steel, Wear, vol. 274-275, 442-451. DOI: 10.1016/j.wear.2011.11.010.

3. Bobzin K. (2017). High-performance coating for cutting tools, CIRP Journal of Manufacturing Science and Technology, 18, 1-9. DOI: 10.1016/j. 
cirpj.2016.11.004.

4. Cui X., Guo J., Zheng J. (2016). Optimization of geometry parameters for ceramic cutting tools in intermittent turning of hardened steel, Maerials\&Design, 92, 424-437. DOI: 10.1016/j. matdes.2015.12.089.

5. Ay H., Yang W.J. (1998). Heat transfer and life of metal cutting tools in turning, International Journal of Heat and Mass Transfer, 41(3), 613-623. DOI: 10.1016/S0017-9310(97)00105-1.

6. Su Y., He N., Li L., Li X.L. (2006). An experimental investigation of effects of cooling/lubrication conditions on tool wear in high-speed end milling of Ti-6Al-4V, Wear, 261(7-8), 760-766. DOI: 10.1016/j.wear.2006.01.013.

7. Sebok M., Kucera M., Korenciak D., Gutten M. (2019). Thermal diagnostic systems and their application for analysis of transformer winding. Diagnostyka, 20(2), 49-55, https://doi.org/10.29354/diag/105933.

8. Ueda T., Al Huda M., Yamada K., Nakayuma K., Kudo H. (1999). Temperature Measurement of CBN Tool in Turning of High Hardness Steel, CIRP Annals Manufacturing Technology, 48(1), 63-66. DOI: 10.1016/S0007-8506(07)63132-1.

9. Ghani M.U., Abukhshim N.A., Sheikh M.A. (2008). An investigation of heat partition and tool wear in hard turning of H13 tool steel with CBN cutting tools, The International Journal of Advanced Manufacturing Technology, 39(9), 874-888. DOI: 10.1007/s00170-007-1282-7.

10. Miaa M., Kumar M., Guptabc K., Singhd G., Królczyk G., Pimenovf D.Y. (2018). An aproach to cleaner production for machining hardened steel using different cooling-lubrication conditions, Journal of Cleaner Production, 187, 1069-1081. DOI: 10.1016/j.jclepro.2018.03.279.

11. Miaa M., Dhar N. R. (2018). Effects of duplex jets high-pressure coolant on machining temperature and machinability of Ti-6Al-4V superalloy, Journal of Materials Processing Technology, 252, 688-696. DOI: 10.1016/j.jmatprotec.2017.10.040.

12. Bhatt A., Attia H. (2010). Wear mechanisms of WC coated and uncoated tools in finish turning of Inconel 718, Tribology International, 43(5-6), 1113-1121. DOI: 10.1016/j.triboint.2009.12.053.

13. Hou J., Zhao N., Zhu S. (2011). Influence of Cutting Speed on Flank Temperature during Face Milling of Magnesium Alloy, Materials and manufacturing processes, 26(8), 1059-1063. DOI: 10.1080/10426914.2010.536927.

14. Almeida F., Amaral M., Oliveira F., Silva R. (2006). Machining behavior of silicon nitride tools coated with micro-, submicro- and nanometric HFCVD diamond crystallite sizes, Diamond and Related Materials, 15(11-12), 2029-2034. DOI: 10.1016/j. diamond.2006.08.006.

15. Wang Y., Lei K., Ruan Y., Dong W. (2016). Microstructure and wear resistance of $\mathrm{c}-\mathrm{BN} / \mathrm{Ni}-\mathrm{Cr}-$ Ti composites, International Journal of Refractory Metals and Hard Materials, 54, 98-103, DOI: 10.1016/j.ijrmhm.2015.07.010.

16. Rosinski M., Michalski A. (2012). WCCo/cBN composites produced by pulse plasma sintering method, Journal of Materials Science, 47(20), 7064-7071. DOI: 10.1007/s10853-012-6532-x.

17. Wojciechowski S., Nowakowski Z., Talar R. (2015). Ocena zjawisk fizycznych w procesie toczenia żeliwa sferoidalnego ostrzami z kompozytu WCCo/cBN, Mechanik, 12, 916-919. (in Polish)

18. DOI: 10.17814/mechanik.2015.12.606.

19. Wieczorowski M., Różański L., Gapiński B., Królczyk G.M. (2014). Investigations Regarding the Influence of Surface Topography on Emissive Properties of Material, Aplied Mechanics and Materials, 657, 402-406. DOI: 10.4028/www.scientific.net/AMM.657.402.

20. Majchrowski R., Różański L., Grochalski K. (2015). The Surface 3D parameters to describe the diffuse reflective and emissive properties of selected dielectrics, XXI IMEKO World Congress - full papers, 1268-1271. DOI: 10.21611/qirt.2014.045.

21. Sutter G., Faure L., Molinari A., Ranc N., Pina V. (2003). An experimental technique for the measurement of temperature fields for the orthogonal cutting in high speed machining, International Journal of Machine Tools and Manufacture, 43(7), 671-678. DOI: 10.1016/S0890-6955(03)00037-3.

22. Wałach T.(2008). Emissivity measurements on electronic microcircuits, Measurement, 41, 503-515. DOI: 10.1016/j.measurement.2007.07.001.

23. Majchrowski R., Różański L., Grochalski K. (2017). Apointing of surface topography parameters to describe the diffuse reflective properties of selected dielectrics, Measurement Automation Monitoring - Pomiary Automatyka Kontrola, 63(3), 78-81.

24. Wen C.D., Mudawar I. (2003). Modeling the effects of surface roughness on the emissivity of aluminum alloys, International Journal of Heat and Mass Transfer, 49(23-24), 4279-4289.DOI: 10.1016/j.ijheatmasstransfer.2006.04.037.

25. Sabuga W., Todtenhaupt R. (2001). Effect of roughness on the emissivity of the precious metals silver, gold, palladium, platinum, rhodium, and iridium, High Temperatures-High Pressures, 33(3), 261-269. DOI: 10.1068/htwu371.

26. Huang Z., Zhou W., Tang X., Zhu D., Luo F. (2011). Effects of substrate roughness on infraredemissivity characteristics of $\mathrm{Au}$ films deposited on Ni alloy, Thin Solid Films, 519(10), 3100-3106. DOI: $10.1016 /$ j.tsf.2010.12.157. 
27. Seifter A., Boboridis K., Obst A.W. (2004). Emissivity Measurements on Metallic Surfaces with Various Degrees of Roughness, A Comparison of Laser Polarimetry and Integrating Sphere Reflectometry, International Journal of Thermophysics, 25(2), 547-560. DOI: 10.1023/B:IJOT.0000028489.81327.b7.

28. Majchrowski R., Grochalski K., Rózański L. (2015). The Design Concept of the Laboratory Heater for Studying the Effect of Surface Topography to Emissivity, Measurement Automation Monitoring, 61(6), 176-179.

29. Zagórniak P., Stachurski W., Ostrowski D. (2016). Application of thermographic measurements for the determination of the impact of selected cutting parameters on the temperature in the workipece during milling process. Strojniški vestnik - Journal of Mechanical Engineering, 62(11), 657-66. DOI:10.5545/sv-jme.2015.3259.

30. Struzinkiewicz G. (2013). Analiza poprawności pomiaru temperatury w strefie skrawania w procesie toczenia stali 4H13, Inżynieria Maszyn, 18(4), 72-85. (in Polish)

31. Jakubek B., Barczewski R., Rukat W., Rozanski L., Wrobel M. (2019). Stabilization of vibro-thermal processes during post-production testing of rolling bearings. Diagnostyka, 20(3), 53-62. DOI: $10.29354 /$ diag/111564. 